\title{
Adenomas per colonoscopy and adenoma per positive participant as quality indicators for screening colonoscopy
}

\section{다 (1) $\odot$}

Authors

Shuo Wang1 ${ }^{1}$, Adam S. Kim², Timothy R. Church ${ }^{3}$, David G. Perdue ${ }^{2}$, Aasma Shaukat ${ }^{3,4,5}$

Institutions

1 Division of Epidemiology \& Community Health, School of Public health, University of Minnesota, Minneapolis, Minnesota, United States

2 Minnesota Gastroenterology PA - GI, Minneapolis, Minnesota, United States

3 Environmental Health Sciences, School of Public Health, University of Minnesota, Minneapolis, Minnesota, United States

4 Department of Medicine, School of Medicine, University of Minnesota, Minneapolis, Minnesota, United States

5 Division of Gastroenterology, Minneapolis VA Medical Center, Minneapolis, Minnesota, United States

submitted 19.3.2020

accepted after revision 30.7.2020

\author{
Bibliography \\ Endoscopy International Open 2020; 08: E1560-E1565 \\ DOI 10.1055/a-1261-9074 \\ ISSN 2364-3722 \\ (C) 2020. The Author(s). \\ This is an open access article published by Thieme under the terms of the Creative \\ Commons Attribution-NonDerivative-NonCommercial License, permitting copying \\ and reproduction so long as the original work is given appropriate credit. Contents \\ may not be used for commecial purposes, or adapted, remixed, transformed or \\ built upon. (https://creativecommons.org/licenses/by-nc-nd/4.0/) \\ Corresponding author \\ Aasma Shaukat MD MPH, One-Veterans Drive, 111D, \\ Minneapolis MN 55417, United States \\ Fax: + 1-612-725-2248 \\ shaukat@umn.edu
}

\section{ABSTRACT}

Background and study aims Adenomas per colonoscopy (APC) and adenomas per positive patient (APP) have been proposed as additional quality indicators but their association with adenoma detection rate (ADR) is not well studied. The aim of our study was to evaluate the variability in APC and APP, their association with ADR, and associated risk factors in screening colonoscopies from a community practice. Patients and methods We calculated the APC, APP, and ADR from all screening colonoscopies performed over 5 years. We used adjusted hierarchical logistic regression to assess the association of factors with APC, APP, and ADR.

Results There were 80,915 screening colonoscopies by 60 gastroenterologists. The median (Q1-Q3) APC, APP, and ADR were $0.41(0.36-0.53), 1.33(1.23-1.40)$, and 0.32 $(0.28-0.38)$, respectively. Despite the high correlation between APC and ADR, $47.6 \%$ of endoscopists with the lowest APC had a higher ADR, and no endoscopists with the highest APC had a lower ADR. Of endoscopists with the lowest APP, $74.3 \%$ had a higher ADR and $5.6 \%$ of endoscopists with the highest APP had a lower ADR. Factors associated with higher APC after multivariable adjustment included: older patients age (OR 1.003; $95 \% \mathrm{Cl} 1.002-1.005)$, male patients (OR 1.123; $95 \% \mathrm{Cl} 1.090-1.156$ ), younger endoscopist age (OR 0.943; $95 \% \mathrm{Cl} 0.941-0.945)$, and longer withdrawal time (OR 3.434; $95 \% \mathrm{Cl} 2.941-4.010)$. Factors associated with higher APP were male sex, younger endoscopist age, and longer withdrawal time.

Conclusion APC and APP provides additional information about endoscopist performance. Younger endoscopist age and longer withdrawal time are associated with colonoscopy quality.

\section{Introduction}

Screening colonoscopies can detect and remove polyps [1], and polypectomy during a colonoscopy has been shown to decrease colorectal cancer incidence [2]. The adenoma detection rate (ADR) is a recognized quality indicator for colonoscopy [3]. Multiple studies have assessed colonoscopic practice with ADR and found that higher ADRs were inversely associated with risk of interval colorectal cancer [4-6]. However, there is substan- tial variability in ADR among endoscopists [7]. One previous study reported that ADR may be insufficient to identify the quality of a colonoscopy, because an endoscopist may be less inclined to identify and remove polyps once a single adenoma has been detected [8]. Therefore, two novel quality indicators have been proposed: adenomas per colonoscopy (APC), and adenomas per positive participant (APP) [8]. One recently published meta-analysis of 43 publications with 15,000 colonos- 
copies found that APC and APP were independently associated with adenoma miss rate [9]. However, only one previous study investigated the correlation of APC and APP with ADR, finding APC strongly correlated with ADR $(r=0.94, P<0.01)$, and APP weakly correlated with ADR $(r=0.36, P<0.36)[10]$.

Our primary aim was to investigate the correlation of APC and APP with ADR in a large US screening colonoscopy practice and to elucidate patient-level, endoscopist-level and procedure factors associated with APC, APP, and ADR.

\section{Patients and methods}

\section{Study population and data description}

We collected information on all colonoscopy examinations performed within five ambulatory endoscopy centers (AEC) that were part of a community-based single specialty gastroenterology practice in the Twin Cities of Minnesota (MNGi Digestive Health) over a 5-year period, from January 2008 to December 2012. Only complete screening colonoscopies performed in average-risk individuals 50 years and older were included in this study.

All colonoscopies were performed during 30-minute time slots by endoscopists using standard bowel preparation with one of several oral lavage regimens. Most procedures (98\%) were performed using moderate conscious sedation with midazolam and fentanyl. Endoscopists were not aware of the specific study hypothesis, but all partners had previously signed a partnership agreement that includes an acknowledgement that results of their procedures will be monitored for quality purposes and potentially published without individual attribution. The study was approved by the University of Minnesota institutional review board.

We identified all procedure reports with the term "screening" in the indications field (from a drop-down menu), in addition to a detailed algorithm that uses text word search for all words resembling "screening" or its synonyms that could have been entered as free text in the indication field [7]. We extracted information on quality of preparation (defined as adequate, including descriptions of "good," "excellent," or "fair"; or inadequate, including descriptions of "poor"), completeness of procedure, whether polyps were removed and their size, conscious sedation administered (type and doses) and withdrawal time (defined as time from reaching the cecum to removal of colonoscope from anal verge). Withdrawal time was calculated as average of exams where no polyps were removed per provider. Colonoscopy was defined as "complete" if cecal landmarks were reached and documented. Endoscopist age was calculated at the time of their first colonoscopy included in the study.

\section{Definition of quality parameters}

Adenoma was defined per WHO criteria, as any premalignant lesion that was tubular, villous, or tubulovillous histology or with low- or high-grade intraepthelial neoplasia.

APC was defined as the number of detected adenomas divided by the total number of screening colonoscopies.
APP was defined as the number of detected adenomas divided by the number of screening colonoscopies in which one or more adenomas are detected.

ADR was defined as the number of screening colonoscopies in which one or more adenomas are detected, divided by the total number of screening colonoscopies.

We excluded colonoscopies with missing information about polyp detection. Hyperplastic polyps were excluded.

\section{Statistical Analysis}

We restricted the analysis to the 60 endoscopists who had performed at least 100 screening colonoscopies during the study period with adequate preparation. An average of 1703 colonoscopies per endoscopist were performed during the time period (median 1700). Patients and endoscopists characteristics are described as percentages for categorical variables or means with standard deviations (SD) for continuous variables. Because of the small number of female endoscopists for the years selected, we could not perform analysis by physician gender.

For our primary aim, we generated scatter plots and performed spearman correlation analysis for the correlation of APC, APP with ADR. We divided endoscopists into two groups ( $A D R \geq 25 \%$, or $A D R<25 \%$ ), and divided APC, and APP into four groups based on their quartiles. Then we assessed how many endoscopists with the lowest quartile of APC, or APP had an $A D R \geq 25 \%$. For our second aim, we divided APC, and APP into two groups based on their median, and divided ADR at the cut point of $25 \%$. We used unadjusted and adjusted hierarchical logistic regression to assess the association of patient-level (continuous age, gender: female/male), endoscopist-level (continuous age), and procedure factor (withdrawal time: $<6$ mins $/ \geq 6$ mins) with APC, APP and ADR. All the analyses were performed using Stata/IC software, version 15.1. All statistical tests were two-sided with $P<0.05$ regarded as statistically significant.

\section{Results}

Over 5 years, a total of 80,915 complete screening colonoscopy examinations were performed in the 5 AEC's by 60 gastroenterologists. The median (Q1-Q3) APC, APP, and ADR were 0.41 $(0.36-0.53), 1.33(1.23-1.40)$, and $0.32(0.28-0.38)$, respectively. Demographic data and clinical characteristics for patients and endoscopists are presented in $>$ Table 1. Younger endoscopists were more likely to have higher APC, APP, and ADR. Endoscopists with a longer withdrawal time had higher APC, APP, and ADR. Endoscopists with high APP, ADR and APC were also more likely to be high detectors of sessile serrated adenomas (detection rates for low vs. high APC, APP, and ADR were $5.1 \%$ vs. $8.8 \%(P<0.001), 5.7 \%$ vs. $7.9 \%(P<0.001), 3.5 \%$ vs. $7.3 \%(P<0.001)$, respectively) and advanced adenomas (detection rates for low vs. high APC APP, and ADR were $4.4 \%$ vs. $7.4 \%(P<0.001), 5.1 \%$ vs. $6.4 \%(P<0.001)$, and $3.0 \%$ vs. $6.2 \%$ $(P<0.001)$, respectively). 
- Table 1 Demographic data and clinical characteristics of patients and physicians.

\begin{tabular}{|c|c|c|c|c|c|c|}
\hline & Low APC & High APC & Low APP & High APP & Low ADR & High ADR \\
\hline Variable $^{1}$ & $(N=44,692)$ & $(N=36,223)$ & $(N=40,402)$ & $(N=40,513)$ & $(N=11,372)$ & $(N=69,543)$ \\
\hline \multicolumn{7}{|l|}{ Patients characteristics } \\
\hline Age, years $\pm S D$ & $59.22 \pm 8.70$ & $59.29 \pm 8.76$ & $59.32 \pm 8.75$ & $59.19 \pm 8.71$ & $59.28 \pm 8.72$ & $59.24 \pm 8.73$ \\
\hline Men (\%) & $44.9 \%$ & $47.5 \%$ & $45.2 \%$ & $47.0 \%$ & $39.7 \%$ & $47.1 \%$ \\
\hline \multicolumn{7}{|l|}{ Physician characteristics } \\
\hline Age, years $\pm S D$ & $52.11 \pm 9.28$ & $47.04 \pm 9.41$ & $51.11 \pm 8.29$ & $48.64 \pm 10.73$ & $57.73 \pm 12.10$ & $48.57 \pm 8.54$ \\
\hline \multicolumn{7}{|l|}{ Procedure Characteristics } \\
\hline Adequate preparation (\%) & $99.3 \%$ & $99.2 \%$ & $99.3 \%$ & $99.3 \%$ & $99.3 \%$ & $99.3 \%$ \\
\hline Withdrawal time, mins $\pm S D$ & $9.19 \pm 10.53$ & $11.39 \pm 10.96$ & $9.13 \pm 8.22$ & $11.22 \pm 12.75$ & $9.50 \pm 8.16$ & $10.29 \pm 11.15$ \\
\hline \multicolumn{7}{|l|}{ Histology Type (\%) } \\
\hline Sessile serrated adenoma & $5.1 \%$ & $8.8 \%$ & $5.7 \%$ & $7.9 \%$ & $3.5 \%$ & $7.3 \%$ \\
\hline Advanced adenoma & $4.4 \%$ & $7.4 \%$ & $5.1 \%$ & $6.4 \%$ & $3.0 \%$ & $6.2 \%$ \\
\hline Cancer & $0.4 \%$ & $0.5 \%$ & $0.5 \%$ & $0.4 \%$ & $0.3 \%$ & $0.4 \%$ \\
\hline
\end{tabular}

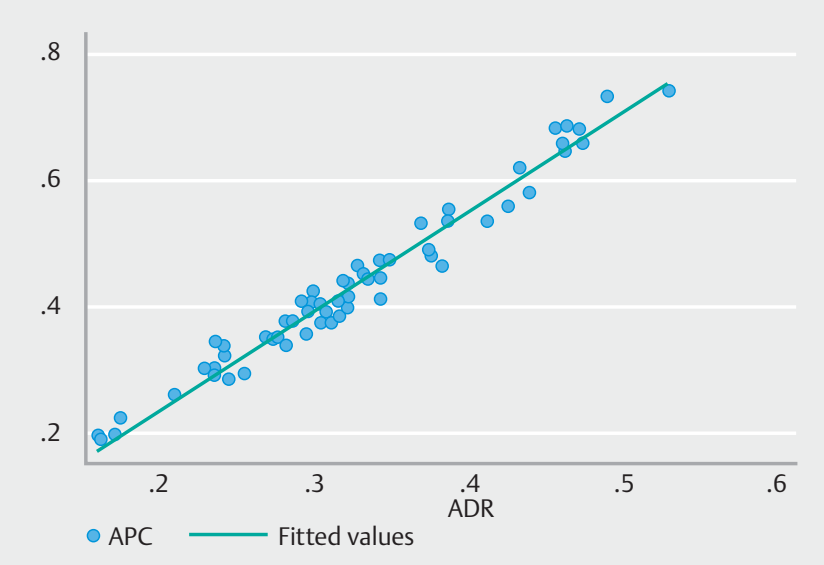

- Fig. 1 Correlation of APC with ADR ( $r=0.97, P<0.001)$.

\section{Correlation of APC, and APP with ADR}

The correlations of APC, and APP with ADR are shown in $>$ Fig. 1 and $>$ Fig. 2. We found an excellent correlation of APC with ADR $(r=0.97, P<0.001)$, and a moderate correlation of APP with ADR $(r=0.59, P<0.01)$. The number of endoscopists with the lowest (quartile 1) and highest (quartile 4) APC and APP stratified by higher and lower ADR are shown in $>$ Table 2. About $47.6 \%$ of endoscopist with the lowest APC had a higher ADR, and no endoscopists with the highest APC had a lower ADR. About $74.3 \%$ of endoscopists with the lowest APP had a higher ADR, and about $5.6 \%$ of endoscopists with the highest APP had a lower ADR.

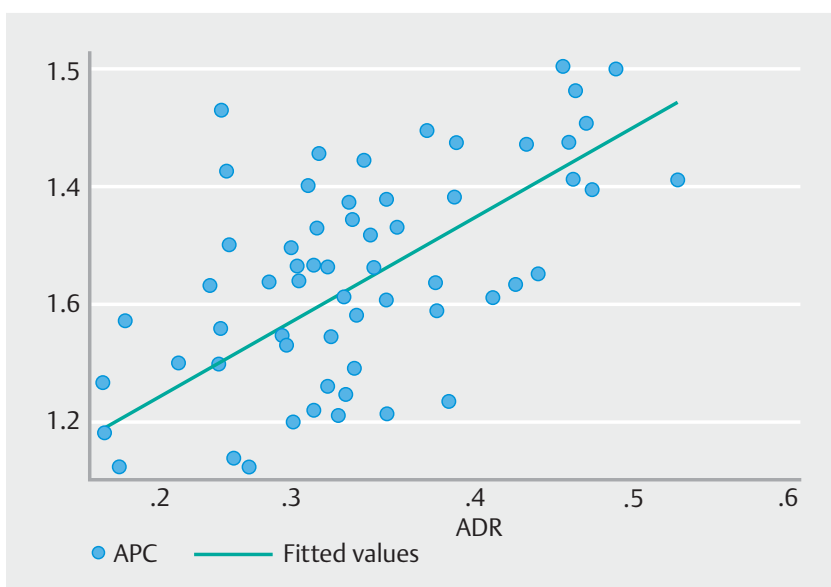

Fig. 2 Correlation of APP with ADR $(r=0.57, P<0.01)$.

\section{Association of factors with APC, APP, and ADR}

The unadjusted and adjusted association of patient-level, endoscopist-level, and procedure factors with APC, APP, and ADR were presented in $\triangleright$ Table 3, $>$ Table 4, and $\triangleright$ Table 5, respectively. Factors associated with higher APC after adjusting multivariable including: older patients age (OR 1.003; $95 \% \mathrm{CI}$ $1.002-1.005$ ), male patients (OR 1.123; $95 \% \mathrm{Cl} 1.090-1.156)$, younger endoscopist age (OR 0.943; $95 \% \mathrm{Cl} 0.941-0.945)$, and longer withdrawal time (OR 3.434; $95 \%$ Cl 2.941-4.010). Factors associated with higher APP after adjusting multivariable including: male patients (OR 1.059; $95 \% \mathrm{Cl} 1.039$ - 1.099), younger endoscopist age (OR 0.972; $95 \% \mathrm{Cl} 0.971-0.974)$, and longer withdrawal time (OR 2.538; $95 \% \mathrm{Cl} 2.218-2.902)$. Factors associated with higher ADR after adjusting multivariable including: 
- Table 2 Number of physicians with lowest quartile and highest quartile had lower and higher ADR.

\begin{tabular}{|l|l|l|}
\hline \multicolumn{3}{|c|}{ ADR } \\
\hline & $<25 \%$ & $\geq 25 \%$ \\
\hline APC & & \\
\hline Q1, N(\%) & $11,372(52.4 \%)$ & $10,332(47.6 \%)$ \\
\hline Q4, N\%) & $0(0.0 \%)$ & $19,192(100.0 \%)$ \\
\hline APP & & \\
\hline Q1, N(\%) & $5,224(25.7 \%)$ & $15,087(74.3 \%)$ \\
\hline Q4, N(\%) & $1,104(5.6 \%)$ & $18,459(94.4 \%)$ \\
\hline $\begin{array}{l}\text { APC, adenomas per colonoscopy; APP, adenomas per positive participant; } \\
\text { ADR, adenoma detection rate; Q1, highest quartile; Q4, lowest quartile; } \\
\text { N, sample size. }\end{array}$ & \\
\hline
\end{tabular}

older patients age (OR 1.005; $95 \% \mathrm{Cl} 1.002-1.007)$, male patients (OR 1.485; $95 \% \mathrm{Cl} 1.421-1.553)$, younger endoscopist age (OR 0.893; $95 \% \mathrm{Cl} 0.891-0.895)$, and longer withdrawal time (OR 1.390; $95 \% \mathrm{Cl} 1.176-1.644)$.

\section{Discussion}

In this large, community-based study of 60 endoscopists performing screening colonoscopies, rates APC, APP, and ADR for individual endoscopists were variable. For the two new quality indicators in colonoscopy, APC was highly correlated with ADR and APP was moderately correlated with ADR. Factors associated with higher APC, APP, and ADR were younger patients age, male patients, younger endoscopist age, and longer withdrawal time ( $\geq 6$ mins).

We found APC highly correlated with $\operatorname{ADR}(r=0.97, P<0.001)$. Our results are consistent with other reports in the literature. In a prospective study in Korea (28 colonoscopists), Park et al. found that APC was significantly correlated with ADR $(r=0.82$, $P<0.001$ ) [11]. In a US study with 21,766 colonoscopies performed by 20 endoscopists, Kahi et al. found that APC and ADR were highly correlated $(r=0.91, P<0.001)$ [12]. In an Austrian study with 44,142 colonoscopies performed by 202 endoscopists, Gessl et al. found that APC was strongly correlated with ADR $(r=0.94, P<0.01)[10]$. We also found that APP was moderately correlated with ADR $(r=0.57, P<0.01)$. A retrospective study including 2116 colonoscopies performed by 6 endoscopists found that APP was not correlated with ADR [13]. We found no endoscopist with highest APC had a lower ADR. However, we also performed analyses stratified by high and low APC and AAP, which provide additional information beyond the correlation alone. We found that $47.6 \%$ of endoscopists with low APC and $74 \%$ of endoscopists with low APP had a higher ADR, suggesting these endoscopists are good at finding one polyp but not multiple polyps, lending support to the "one and done" phenomenon and that both APP and APC may be a good measure beyond ADR, to distinguish high performers. Taken together, our findings suggest that although ADR may be sufficient in capturing the quality of colonoscopy, both APC and APP further distinguish high performers beyond an adequate ADR. With advances in technology, adoption of artificial intelligence and other computer-aided assistance for polyp detection, ADR alone may no longer be sufficient in distinguishing high from low performers, and there is an unmet need to develop and validate newer quality indicators.

- Table 3 Unadjusted and adjusted* association of factors with adenoma per colonoscopy.

\begin{tabular}{|c|c|c|c|c|c|c|}
\hline & \multirow{2}{*}{$\begin{array}{l}\text { Low APC } \\
\mathrm{N}\end{array}$} & \multirow{2}{*}{$\begin{array}{l}\text { High APC } \\
\text { N }\end{array}$} & \multicolumn{2}{|l|}{ Unadjusted } & \multicolumn{2}{|l|}{ Adjusted } \\
\hline & & & OR $(95 \% \mathrm{Cl})$ & $P$ value & OR $(95 \% \mathrm{Cl})$ & $P$ value \\
\hline \multicolumn{7}{|c|}{ Patients characteristics } \\
\hline Age & 44,692 & 36,223 & $1.000(0.999,1.003)$ & 0.235 & $1.003(1.002,1.005)$ & $<0.001$ \\
\hline \multicolumn{7}{|l|}{ Gender } \\
\hline Female & 24,619 & 19,025 & 1.000 (ref) & & 1.000 (ref) & \\
\hline Male & 20,072 & 17,196 & $1.108(1.078,1.140)$ & $<0.001$ & $1.123(1.090,1.156)$ & $<0.001$ \\
\hline \multicolumn{7}{|c|}{ Physicians characteristics } \\
\hline Age & 44,692 & 35,319 & $0.944(0.942,0.945)$ & $<0.001$ & $0.943(0.941,0.945)$ & $<0.001$ \\
\hline \multicolumn{7}{|c|}{ Procedure characteristics } \\
\hline \multicolumn{7}{|c|}{ Withdrawal time } \\
\hline$<6$ mins & 863 & 248 & 1.000 (ref) & & 1.000 (ref) & \\
\hline$\geq 6$ mins & 42,269 & 34,858 & $2.870(2.490,3.307)$ & $<0.001$ & $3.434(2.941,4.010)$ & $<0.001$ \\
\hline
\end{tabular}


Table 4 Unadjusted and adjusted* association of factors with adenoma per positive colonoscopy.

\begin{tabular}{|c|c|c|c|c|c|c|}
\hline & \multirow{2}{*}{$\begin{array}{l}\text { Low APP } \\
\text { N }\end{array}$} & \multirow{2}{*}{$\begin{array}{l}\text { High APP } \\
\text { N }\end{array}$} & \multicolumn{2}{|l|}{ Unadjusted } & \multicolumn{2}{|l|}{ Adjusted } \\
\hline & & & OR $(95 \% \mathrm{Cl})$ & $P$ value & OR $(95 \% \mathrm{Cl})$ & $P$ value \\
\hline \multicolumn{7}{|c|}{ Patients characteristics } \\
\hline Age & 40,402 & 40,513 & $0.998(0.997,1.000)$ & 0.036 & $1.000(0.998,1.001)$ & 0.760 \\
\hline \multicolumn{7}{|l|}{ Gender } \\
\hline Female & 22,160 & 21,484 & 1.000 (ref) & & 1.000 (ref) & \\
\hline Male & 18,241 & 19,027 & $1.076(1.047,1.106)$ & $<0.001$ & $1.069(1.039,1.099)$ & $<0.001$ \\
\hline \multicolumn{7}{|c|}{ Physician characteristics } \\
\hline Age & 39,912 & 40,099 & $0.974(0.972,0.975)$ & $<0.001$ & $0.973(0.971,0.974)$ & $<0.001$ \\
\hline \multicolumn{7}{|c|}{ Procedure characteristics } \\
\hline \multicolumn{7}{|c|}{ Withdrawal time } \\
\hline$<6$ mins & 794 & 317 & 1.000 (ref) & & 1.000 (ref) & \\
\hline$\geq 6$ mins & 38,526 & 38,871 & $2.545(2.233,2.901)$ & $<0.001$ & $2.538(2.218,2.902)$ & $<0.001$ \\
\hline
\end{tabular}

- Table 5 Unadjusted and adjusted* association of factors with adenoma detection rate.

\begin{tabular}{|c|c|c|c|c|c|c|}
\hline & \multirow{2}{*}{$\begin{array}{l}\text { Low ADR } \\
\mathrm{N}\end{array}$} & \multirow{2}{*}{$\begin{array}{l}\text { High ADR } \\
\mathrm{N}\end{array}$} & \multicolumn{2}{|l|}{ Unadjusted } & \multicolumn{2}{|l|}{ Adjusted } \\
\hline & & & OR $(95 \% \mathrm{Cl})$ & $P$ value & OR $(95 \% \mathrm{Cl})$ & $P$ value \\
\hline \multicolumn{7}{|c|}{ Patient characteristics } \\
\hline Age & 11,372 & 69,543 & $1.000(0.997,1.002)$ & 0.677 & $1.005(1.002,1.007)$ & $<0.001$ \\
\hline \multicolumn{7}{|l|}{ Gender } \\
\hline Female & 6,854 & 36,790 & 1.000 (ref) & & 1.000 (ref) & \\
\hline Male & 4,517 & 32,751 & $1.351(1.297,1.406)$ & $<0.001$ & $1.485(1.421,1.553)$ & $<0.001$ \\
\hline \multicolumn{7}{|c|}{ Physician characteristics } \\
\hline Age & 11,372 & 68,639 & $0.896(0.894,0.898)$ & $<0.001$ & $0.893(0.891,0.895)$ & $<0.001$ \\
\hline \multicolumn{7}{|c|}{ Procedure characteristics } \\
\hline \multicolumn{7}{|c|}{ Withdrawal time } \\
\hline$<6$ mins & 215 & 896 & 1.000 (ref) & & 1.000 (ref) & \\
\hline$\geq 6$ mins & 10,771 & 66,356 & $1.478(1.272,1.718)$ & $<0.001$ & $1.390(1.176,1.644)$ & $<0.001$ \\
\hline
\end{tabular}

We found that endoscopist age was statistically significantly associated with APC, AAP and ADR. Ours is the first study to report physician age and association with APC and AAP. Several previous studies investigated the association of endoscopist' age with $A D R$, but the results were inconsistent. In a retrospective study with 104,618 colonoscopies performed by 201 physicians, Mehrotra et al. found that physicians with less than 9 years since their residency have a higher ADR than physicians who have 25 to 51 years of practice $(P=0.004)$ [14]. Whether this is due to enhanced training of colonoscopy procedure for younger endoscopists, or technical skills of younger endoscopist is not known. However, in the COLONPREV study (3,838 colonoscopies performed by 48 endoscopists), Jover et al. found that older physician age was associated with higher ADR (OR 1.06; 95\% Cl 1.01-1.11) [15]. Our findings need to be confirmed in future studies and the role of endoscopist 
age on performance of colonoscopy needs to be further studied.

The strengths of our study are the large sample size of colonoscopies, community dwelling, average risk screening population and prospectively collected data. We collected information on patient-level, endoscopist-level and procedure-level factors and detailed information on histology of polyps and withdrawal times. The first limitation of these results is that we only included 60 endoscopists in a single practice. Second, there may be residual confounding of the association of factors with APC, $A P P$, and ADR for which we are unable to account or control, such as patient race, diet, body mass index, family history, and lifestyle. Finally, although this is one of the largest communitybased endoscopy practices in the United States, whether our results are generalizable to the population is unknown.

\section{Conclusion}

In summary, APC and ADR were highly correlated, and adenomas per positive participant and ADR was moderately correlated. Younger endoscopist age and longer withdrawal time ( $\geq 6$ mins) were statistically significantly associated with colonoscopy quality. These findings suggest that in addition to ADR, APC and APP provide additional information on endoscopist performance and need to be validated as potential quality indicators.

\section{Acknowledgement}

Supported by a VA HSR\&D grant (AS) CIN 13-406

\section{Competing interests}

The authors declare that they have no conflict of interest.

\section{References}

[1] Jang JY, Chun HJ. Bowel preparations as quality indicators for colonoscopy. World J Gastroenterol 2014; 20: 2746-2750

[2] Winawer S], Zauber AG, Ho MN et al. Prevention of colorectal cancer by colonoscopic polypectomy. The National Polyp Study Workgroup. N Engl J Med 1993; 329: 1977-1981

[3] Jrebi NY, Hefty M, Jalouta T et al. High-definition colonoscopy increases adenoma detection rate. Surg Endosc 2017; 31: 78-84

[4] Corley DA, Levin TR, Doubeni CA. Adenoma detection rate and risk of colorectal cancer and death. N Engl J Med 2014; 370: 2541

[5] Kaminski MF, Regula J, Kraszewska E et al. Quality indicators for colonoscopy and the risk of interval cancer. N Engl J Med 2010; 362: 1795-1803

[6] Kaminski MF, Wieszczy P, Rupinski M et al. Increased rate of adenoma detection associates with reduced risk of colorectal cancer and death. Gastroenterology 2017; 153: 98-105

[7] Shaukat A, Oancea C, Bond JH et al. Variation in detection of adenomas and polyps by colonoscopy and change over time with a performance improvement program. Clin Gastroenterol Hepatol 2009; 7: $1335-1340$

[8] Aniwan S, Orkoonsawat P, Viriyautsahakul V et al. The secondary quality indicator to improve prediction of adenoma miss rate apart from adenoma detection rate. Am J Gastroenterol 2016; 111: $723-$ 729

[9] Zhao S, Wang S, Pan P et al. Magnitude, risk factors, and factors associated with adenoma miss rate of tandem colonoscopy: a systematic review and meta-analysis. Gastroenterology 2019; 156: 1661-1674.e1611

[10] Gessl I, Waldmann E, Penz D et al. Evaluation of adenomas per colonoscopy and adenomas per positive participant as new quality parameters in screening colonoscopy. Gastrointest Endosc 2019; 89: 496-502

[11] Park SK, Kim HY, Lee CK et al. Comparison of adenoma detection rate and adenoma per colonoscopy as a quality indicator of colonoscopy. Scand J Gastroenterol 2016; 51: 886-890

[12] Kahi C], Vemulapalli KC, Johnson CS et al. Improving measurement of the adenoma detection rate and adenoma per colonoscopy quality metric: the Indiana University experience. Gastrointest Endosc 2014; 79: 448-454

[13] Abdelfatah MM, Elhanafi S, Zuckerman MJ et al. Correlation between adenoma detection rate and novel quality indicators for screening colonoscopy. A proposal for quality measures tool kit. Scand J Gastroenterol 2017; 52: 1148-1157

[14] Mehrotra A, Morris M, Gourevitch RA et al. Physician characteristics associated with higher adenoma detection rate. Gastrointest Endosc 2018; 87: 778-786.e775

[15] Jover R, Zapater P, Bujanda L et al. Endoscopist characteristics that influence the quality of colonoscopy. Endoscopy 2016; 48: 241-247 